\title{
DEMONIZAÇÃO DA POLÍTICA OU A POLÍTICA DEMONIZADA? OS EVANGÉLICOS E AS ELEIÇÕES FEDERAIS DE 2006
}

\author{
Marcelo Tadvald
}

Resumo: O estudo versa sobre a inserção dos evangélicos no campo político e sua participação no pleito de 2006 para a Câmara dos Deputados Federais. Como justificativa notória para tal inserção, os evangélicos percebem a esfera pública como uma dimensão do social sujeita as influências maléficas, em especial o campo político, este que já possui uma imagem bastante desacreditada socialmente. Tal inserção no político toma a forma de uma verdadeira cruzada evangélica contra as forças do mal presentes neste campo. Denunciados em diversos casos de corrupção, diversos políticos evangélicos não conseguiram se eleger ou nem mesmo foram lançados candidatos por suas igrejas, o que diminuiu sensivelmente a composição desta bancada federal depois do pleito de 2006. Este texto realiza alguns apontamentos que visam aclarar este fenômeno.

Palavras-chave: Religião e política; evangélicos; eleiçōes federais de 2006.

Entrai pela porta estreita

(larga é a porta, e espaçoso o

caminho que conduz para a perdição, e são muitos os que entram por ela)...

Mateus 7.13

\section{PRIMEIRAS PALAVRAS}

Já em 1832, quando Tocqueville escreveu A Democracia na América, observava-se desde aquela época uma tendência de individualizaçáo do comportamento político, o que em realidade deveria encorajar a apatia política. Neste sentido, a apatia podia ser entendida como um campo aberto e fértil para o cultivo de ideologias e direcionamentos que incidissem sobre o comportamento político e a escolha do voto,à medida que a idéiada democraciaia se desenvolvendo ao longo do século XX. Tal sentido ainda se mostra atual, como as pesquisas sobre esta temática procuram mostrar (ver, por exemplo, os estudos de Baquero, 2000 e de Francisco,

\footnotetext{
* Doutorando do Programa de Pós-graduação em Antropologia Social, UnB. Pesquisador do Núcleo de Estudos da Religião (NER-PPGAS-UFRGS).
} 
2006). O que de certo deve contribuir decisivamente para este processo de descrédito latente que possui o campo político no Brasil e não obstante, na América Latina (Ribeiro, 2002).

Alejandro Frigerio (1993) em certa oportunidade indicou que no processo de conversão religiosa, em particular no caso pentecostal, ocorre uma es pécie de "lavagem cerebral", entendida como uma metáfora utilizada para desqualificar formas religiosas antagônicas. Tal "lavagem cerebral" fornece novos códigos de sentido, que devem ser internalizados pelos convertidos. Dada a inserção de diferentes denominaçôes evangélicas no campo político, e da necessidade da conquista de votos para consumar tal inserção, nada mais natural do que a imbricação de um discurso político com um discurso religioso, ainda que sob as bases de u ma "lavagem cerebral". Em tal contexto, entretanto, seria conveniente tomar a natureza da campanha eleitoral de certas igrejas pentecostais como formas utilitárias de "lava gem cerebral"? Se o for, dentro do campo político e de seus jogos intrínsecos, aonde cada ator luta a guerra com as armas que possui pela conquista de legitimidade que reflete na conquista de votos, ainda que dentro de certas regras (nem sempre seguidas à risca por todos esses atores), o que não poder ia ser qualificado como "lavagem cerebral"? A partir de tais premissas, acredito que o comportamento eleitoral dos evangélicos deva ser percebido sobre outras bases, que levem em conta especialmente os trâmites eleitoreiros inerentes a cada igreja, ainda que em diversos aspectos tais processos se assemelhem, tal como mostrado por Ari Oro em certa ocasião (Oro, 2001).

\section{UM CAMPO DEMONÍACO?}

Para aqueles que estão mais acostumados com a temática relacionada aos evangélicos e ao campo político, são notórias as principais justificativas dada por estes para sua inserção neste campo. A principal delas consiste na percepção do campo político como uma arena sujeita e mesmo tomada pelas influências demoníacas. A demonização da política por parte dos evangélicos, em realidade, ecoa uma semântica nacional que ao seu modo também demoniza este campo. No momento em que tal discurso é proferido pelos bispos, pastores e outros sujeitos (então) políticos dentro de seus templos, este deve representar, para uma população de fiéis brasileiros e mesmo latino-americanos, aquilo que de alguma forma já se encontra internalizado em sua percepção sobre o campo político. Se por um lado existe esta demonização da política por todos nós, no caso dos evangélicos, sua cosmologia e teologia próprias fornecem um sentido razoável e encontram ressonância quase que imediata no comportamento político desses adeptos. Em realidade, tal forma discursiva, à sua maneira particular, foi (e deverá ser por muito tempo) utilizada por outros tantos postulantes aos cargos políticos nas eleições. Ao assistir a propaganda eleitoral obrigatória deste último pleito (e dos anteriores também), não raro candidatos de todas as procedências se apresentavam como os "honestos", "moralizadores da política", "aqueles que realmente trabalhariam para o povo", “os imunes à corrupção", enfim, um discu rso que os aproxima de uma dimensão quase que "imaculada", uma vez que tais candidatos são postulantes à entrada em uma arena vista como profana e corrompida. Semanticamente, qual a diferença com o discurso pentecostal? Nenhuma, de fato.

Debates do NER, Porto Alegre, ANo 7, n. 10, p. 79-88, jul./Dez. 2006 
A demonização da política advém, portanto, deste déficit e deste desencantamento que, para alguns autores, como Patrick Michel (1997), é tomado como um fenômeno global. A religião, sempre sementeira de novas energias, parafraseando Renato Janine Ribeiro (2002), imbrica-se de forma quase que natural e mesmo esperada no campo político, área desacreditada e "desacreditável" por excelência den tro do imaginário coletivo de nossa sociedade. Visto de outra maneira, e conforme sugeriu P. Michel, o que se observa com mais propriedade atualmente não é tanto (ou somente) um processo de sacralização do político, mas antes uma politização do religioso. Diferentes estudos comprovam esta idéia. Portanto, é possível estudarmos os candidatos católicos, os candidatos afro-religiosos, os candidatos esotéricos, além dos evangélicos, pelo simples fato deles existirem, ou, dito de outra forma, pelo simples fato do religioso ter se politizado.

Neste sentido, tanto o religioso quanto o político tendem a sacralizar o espaço público. Tanto um campo quanto o outro parecem perceber este espaço sagrado como sujeito às vicissitudes do profano. Os evangélicos tão somente construíram sua representação deste espaço público (sacralizado) como tomado de injustiças e já profanado pelas forças do mal.

No processo maior de individualização do comportamento e da composição do sistema simbólico das pessoas, tanto as opções religiosas quanto as opçóes políticas também se mostram deveras individualizadas. Contudo, tais opções parecem se encontrar legitimamente imbricadas, especialmente nos casos em que a opção religiosa se constitui numa das dimensões mais constitutivas da identidade social de determinados sujeitos. Este parece ser o caso, por exemplo, dos evangélicos. Tal perspectiva, também, não entra em choque com aqueles paradigmas sobre a modernidade que apostam na individualização das escolhas, como se todos esses sujeitos possuíssem a mesma capacidade de agência, aliás, concepção adjacente à lógica idealizada da democracia e de sua equanimidade entre os sujeitos (cidadãos), isto porque sem instituiçóes, comunidades de sentido e referências culturais de naturezas diferentes, os sujeitos, dentro desta lógica absolutamente individualista, nada mais seriam do que estrelas aprisionadas numa abóbada celeste sem capacidade de se orientar na sua realidade. Dito de outra forma, o campo religioso ainda detém um papel estratégico neste processo de significação do mundo. E o campo político faz parte deste mundo.

Uma vez o campo político pertencer à esfera pública, e uma vez existirem forças maléficas atuando nos espaços públicos, conforme acreditam os evangélicos, adentrar neste espaço se trata de uma missão de combate contra estas forças: é preciso realizar uma mobilização contra elas. Dado que o pentecostalismo alimenta as mobilizações identitárias como poucas religiosidades conseguem fazer hoje em dia, de maneira massiva e através da mobilização dos imaginários que se revelam em culturas heterogêneas e dentro de contextos políticos que aparentam diferenças radicais (Corten; Mary, 2000), é possível que sua entrada nesta esfera pública se realize através de um sofisticado e pragmático programa político que se alicerça em uma organizada base eleitoral formada pelos adeptos destas religiōes. A partir deste modelo, e recordando que os pentecostais tendem a demonizar quase tudo e todos: feiticeiros, umbandistas, intelectuais, artistas, cientistas, antropólogos e (claro) também os políticos, sua entrada no campo da política se torna, na esfera do discurso e da prática, uma verdadeira cruzada de combate e de sublevação das forças do mal. Seriam, portanto, os evangélicos os únicos imunes a demonização?

Debates do NER, Porto Alegre, ANo 7, N. 10, P. 79-88, jul./DeZ. 2006 
A necessidade de "moralização" do espaço público projetado pelos eva ngélicos se consubstancia numa espécie de programa político, conforme mencionei. E note-se que tal como estas religiões se tornaram artigos brasileiros de exportação, não somente para os demais países da América Latina, mas também para outros tantos do mundo, como os da África principalmente, exporta-se conjuntamente com estas cosmologias e teologias pentecostais sua percepção do campo político e seu programa que deve incidir sobre ele. No caso específico da América Latina, conforme sugeriu André Corten (1996), o pentecostalismo conseguiu modificar a base teológica-política desta região. Um dos fatores que podem explicar tal processo consiste no sentimento proporcionado por tais igrejas de aproximar as pessoas da esfera política. Através de tal cosmologia e teologia, os evangélicos podem se sentir como mais participativos do campo político. Este fato é importante por duas razões que de fato se encontram interligadas: por um lado, dentro da própria lógica democrática, são eleitas pessoas que devem nos representar; por outro lado, é sabido através de diversos estudos (por exemplo, o de Moisés, 1995, Francisco, 2006 e o relatório do PNUD, 2004) que as classes populares são aquelas que se percebem menos representadas dentro da arena política. Ora, sabemos que são justamente as pessoas provenientes destes segmentos sociais aquelas que constituem a base de adeptos das religiōes pentecostais. Dentro deste contexto, é como oferecer comida ao faminto.

Dado que o pentecostalismo "toca" (a expressão - toucher - é de Corten, 1996) as camadas mais pobres da população, e de forma massiva como se verificou historicamente, também é preciso observar que atualmente existem denominações religiosas que se endereçam mais diretamente às classes média/alta. Todo este contexto permite a constituiçáo de uma sofisticada base eleitoral, seja no sentido da formação de um trabalho organizado e militante, seja no sentido de angariação de fundos utilizados nas campanhas. Para André Corten: "o pentecostalismo introduz na vida uma dimensão há muito tempo relegada em nome da tolerância: a paixão. A conversão não é uma simples ilusão. O discurso pentecostal é um discurso que produz a paixão. É o que consagra sua força" (Corten, 1996, p. 31, tradução minha).

Esta paixão inerente ao processo de conversão pentecostal historicamente se refletiu nas urnas. De modo que, a bancada evangélica federal vinha em constante ascensão desde as eleições de 1989, chegando no seu auge nas eleições de 2002, com 60 deputados e três senadores, sem contar os parlamentares evangélicos que não aderiram à frente. Contudo, parece que diversos políticos evangélicos não se mostraram tão imunes assim ao campo demonizado da política, o que também se refletiu nas urnas apuradas em 2006.

\section{A BANCADA EVANGÉLICA FEDERAL DEPOIS DO PLEITO DE 2006}

Conforme noticiado no sítio do Terra (consultado em 17/10/2006), a bancada evangélica sofreu uma redução de $75 \%$ na Câmara dos Deputados nestas últimas eleições. Em parte, explica-se esta drástica redução na composição da bancada devido ao escândalo "das Sanguessugas", em que diversos parlamentares da bancada evangélica tiveram seus nomes

Debates do NER, Porto Alegre, ANo 7, n. 10, p. 79-88, jul./Dez. 2006 
envolvidos com a venda superfaturada de ambulâncias (16 indicados pela CPI, exatamente). Para se ter uma idéia, apenas 15 dos 60 deputados, ou 25\% dos parlamentares que compóe a Frente Parlamentar Evangélica continuarão no cargo depois de $1^{\circ}$ de janeiro. Somados os evangélicos eleitos neste último pleito, a bancada deverá contar com um número sensivelmente inferior à composição atual. Não obstante, nenhum dos reeleitos estava com o nome envolvido nestes escândalos mais recentes à época das eleiçôes. O quadro a seguir mostra a atual composição da Câmara dos Deputados Federais, em que, de acordo com o Departamento Intersindical de Assessoria Parlamentar (DIAP), dos 30 parlamentares integrantes da bancada evangélica na Câmara, 17 deputados foram reeleitos e 13 deputados são estreantes:

Quadro I - Bancada Evangélica da Câmara Federal a partir de 2006

\begin{tabular}{|c|c|c|c|}
\hline Deputado & Partido/ Estado & Denominação & Mandato \\
\hline Arolde de Oliveira & PFL/ RJ & Batista & Reeleito \\
\hline Bispo Antônio Bulhões & PMDB/ SP & IURD & Novo \\
\hline Bispo Rodovalho & PFL/ DF & Sara Nossa Terra & Novo \\
\hline Carlos William & PTC/ MG & Maranata & Reeleito \\
\hline Dona Íris Rezende & PMDB/ GO & Sem denominação & Novo \\
\hline Dr. Antonio Cruz & PP/ MS & Assembléia de Deus & Reeleito \\
\hline Dr. Nechar & PV/ SP & Assembléia de Deus & Novo \\
\hline Edinho Montemor & PSB/ SP & Batista & Reeleito \\
\hline Eduardo Cunha & PMDB/ RJ & Sara Nossa Terra & Reeleito \\
\hline Filipe Rio de Cara Nova & PSC/ RJ & Assembléia de Deus & Novo \\
\hline Flávio Bezerra & PMDB/ CE & IURD & Novo \\
\hline George Hilton & PP/ MG & IURD & Novo \\
\hline Gilmar Machado & PT/ MG & Batista & Reeleito \\
\hline Henrique Afonso & PT/ AC & Presbiteriano & Reeleito \\
\hline João Campos & PSDB/ GO & Assembléia de Deus & Reeleito \\
\hline Júlio Redecker & PSDB/ RS & Luterana & Reeleito \\
\hline Jurandyr Loureiro & PSC/ ES & Assembléia de Deus & Novo \\
\hline Léo Vivas & PRB/ RJ & IURD & Novo \\
\hline Leonardo Quintão & PMDB/ MG & Sem denominação & Novo \\
\hline Mário de Oliveira & PSC/MG & Evangelho Quadrangular & Novo \\
\hline Natan Donadon & PMDB/ RO & Batista & Reeleito \\
\hline Neucimar Fraga & PL/ ES & Batista & Reeleito \\
\hline Onyx Lorenzoni & PFL/ RS & Luterano & Reeleito \\
\hline Pastor Lincon Portela & PL/ MG & Batista & Reeleito \\
\hline Pastor Manoel Ferreira & PTB/ RJ & Assembléia de Deus & Novo \\
\hline Paulo Roberto & PTB/ RS & IURD & Novo \\
\hline Silas Câmara & PTB/ AM & Assembléia de Deus & Reeleito \\
\hline Takayama & PMDB/ PR & Assembléia de Deus & Reeleito \\
\hline Walter Pinheiro & PT/ BA & Batista & Reeleito \\
\hline Zequinha Marinho & PSC/ PA & Assembléia de Deus & Reeleito \\
\hline & & & \\
\hline
\end{tabular}

Debates do NER, Porto Alegre, ano 7, N. 10, P. 79-88, Jul./DeZ. 2006 
Conforme nos apresenta este quadro, a Assembléia de Deus é a igreja evangélica com a maior representação na Câmara, com 9 deputados. Em seguida, vem a Igreja Batista com 7, seguida da IURD, com 5 congressistas. Todos os deputados ligados à Assembléia de Deus se candidataram à reeleição, mas somente cinco garantiram vaga na próxima legislatura. Entre os que não se reelegeram, dez são suspeitos de participação na máfia das ambulâncias. Contudo, a bancada desta denominação pode chegar a manter seus nove membros se for confirmada a eleição do Doutor Nechar (PV/ SP). Ou ele ou o presidente nacional do PMDB, deputado Michel Temer, perderá a vaga em razão do deferimento da candidatura de Dimas Ramalho (PSB/ SP), que estava sendo contestada. Além destes parlamentares, a bancada evangélica no Congresso Nacional ainda conta com três senadores: Bispo Marcelo Crivella (PRB/ RJ) da IURD, candidato derrotado ao Governo do Rio Janeiro, Magno Malta (PL/ ES), da Igreja Batista, este que também está sendo investigado na CPI das Sanguessugas e Paulo Octávio (PFL/ DF), da Sara Nossa Terra, que terá que renunciar ao mandato para assumir o cargo de vice-governador do Distrito Federal.

Conforme noticiado pela Redação do Terra (2006), a IURD havia proibido a candidatura à reeleição de parlamentares sob suspeita. Com isso, perdeu 14 postulantes a mais quatro anos na Câmara. Apenas dois membros da igreja tentaram - sem sucesso - a reeleição. O quadro a seguir apresenta os candidatos evangélicos não eleitos no pleito de 2006, mesmo aqueles que haviam concorrido em eleições anteriores mas que não se candidataram nestas últimas:

Quadro II - Candidatos evangélicos não eleitos em 2006

\begin{tabular}{|c|c|c|c|}
\hline Deputado & Partido/ Estado & Denominação & $\begin{array}{c}\text { Candidato } \\
\text { em 2006 }\end{array}$ \\
\hline Adelor Vieira & PMDB/ SC & Assembléia de Deus & Sim \\
\hline Agnado Muniz & $\mathrm{PP} / \mathrm{RO}$ & Assembléia de Deus & Sim \\
\hline Almeida de Jesus & $\mathrm{PL} / \mathrm{CE}$ & IURD & Não \\
\hline Almir Moura & $\mathrm{PFL} / \mathrm{RJ}$ & $\begin{array}{c}\text { I. Internacional } \\
\text { da Graça de Deus }\end{array}$ & Sim \\
\hline Ana Alencar & PSDB/ TO & Sem denominação & Não \\
\hline André Zacharow & PMDB/ PR & Batista & Sim \\
\hline Bispo João Mendes & Sem Partido/ RJ & IURD & Sim \\
\hline Bispo Rodrigues & PL/ RJ & IURD & Renunciou \\
\hline Bispo Vieira Reis & Sem partido/ RJ & IURD & Não \\
\hline Bispo Wanderval & PL/ SP & IURD & Não \\
\hline Cabo Júlio & PMDB/ MG & Assembléia de Deus & Sim \\
\hline Carlos Nader & PL/ RJ & Assembléia de Deus & Sim \\
\hline Costa Ferreira & PSC/MA & Assembléia de Deus & Sim \\
\hline Edna Macedo & PTB/ SP & IURD & Não \\
\hline \multicolumn{2}{|c|}{} & & \\
\hline
\end{tabular}

Debates do NER, Porto Alegre, Ano 7, n. 10, P. 79-88, JUl./Dez. 2006 


\begin{tabular}{|c|c|c|c|}
\hline Gerson Gabrielli & PFL/BA & Batista & Sim \\
\hline Gilberto Nascimento & PMDB/ SP & Assembléia de Deus & Sim \\
\hline Hélio Esteves & $\mathrm{PT} / \mathrm{AP}$ & Protestante & Sim \\
\hline Herculano Anghinetti & $\mathrm{PP} / \mathrm{MG}$ & Batista & Sim \\
\hline Isaías Silvestre & $\mathrm{PSB} / \mathrm{MG}$ & Assembléia de Deus & Sim \\
\hline Jair de Oliveira & PMDB/ ES & $\begin{array}{c}\text { Igreja Cristo } \\
\text { Verdade que Liberta }\end{array}$ & Não \\
\hline Jefferson Campos & PTB/ SP & Quadrangular & Sim \\
\hline João Batista & $\mathrm{PP} / \mathrm{SP}$ & IURD & Sim \\
\hline João Mendes de Jesus & Sem partido/ RJ & IURD & Não \\
\hline João Paulo Gomes da Silva & PL/MG & IURD & Sim \\
\hline Josué Bengtson & PTB/PA & Quadrangular & Sim \\
\hline Lino Rossi & $\mathrm{PP} / \mathrm{MT}$ & Batista & Não \\
\hline Milton Barbosa & PSC/ BA & Assembléia de Deus & Sim \\
\hline Neuton Lima & PTB/ SP & Assembléia de Deus & Sim \\
\hline Nilton Capixaba & $\mathrm{PTB} / \mathrm{RO}$ & Assembléia de Deus & Sim \\
\hline Pastor Amarildo & PSC/ TO & Assembléia de Deus & Sim \\
\hline Pastor Francisco Olímpio & $\mathrm{PSB} / \mathrm{PE}$ & Assembléia de Deus & Sim \\
\hline Pastor Frankembergen Galvão & PTB/RR & Assembléia de Deus & Sim \\
\hline Pastor Heleno & $\mathrm{PL} / \mathrm{SE}$ & IURD & Sim \\
\hline Pastor Jorge Pinheiro & $\mathrm{PL} / \mathrm{DF}$ & IURD & Não \\
\hline Pastor José Divino & Sem partido/ RJ & IURD & Não \\
\hline Pastor Marcos Abramo & $\mathrm{PP} / \mathrm{SP}$ & IURD & Sim \\
\hline Pastor Marcos de Jesus & Sem partido/ PE & IURD & Não \\
\hline Pastor Oliveira Filho & PL/ PR & IURD & Sim \\
\hline Pastor Paulo Gouveia & $\mathrm{PL} / \mathrm{RS}$ & IURD & Sim \\
\hline Pastor Pedro Ribeiro & $\mathrm{PMDB} / \mathrm{CE}$ & Assembléia de Deus & Sim \\
\hline Pastor Reginaldo Germano & $\mathrm{PP} / \mathrm{BA}$ & IURD & Sim \\
\hline Pastor Reinaldo & PTB/ RS & Quadrangular & Sim \\
\hline Paulo Baltaza & PSB/ RJ & Adventista & Sim \\
\hline Philemon Rodrigues & PTB/ PB & Assembléia de Deus & Sim \\
\hline Raimundo Santos & $\mathrm{PL} / \mathrm{PA}$ & Assembléia de Deus & Sim \\
\hline Silas Brasileiro & PMDB/MG & Assembléia de Deus & Sim \\
\hline Simão Sessim & $\mathrm{PP} / \mathrm{RJ}$ & Sem denominação & Sim \\
\hline Wanderval Santos & $\mathrm{PL} / \mathrm{SP}$ & IURD & Sim \\
\hline Zelinda Novaes & $\mathrm{PFL} / \mathrm{BA}$ & IURD & Não \\
\hline Zico Bronzeado & $\mathrm{PT} / \mathrm{AC}$ & Batista & Sim \\
\hline
\end{tabular}


Este quadro permite a observação de diversos fatores, dos quais destaco um em particular: até as eleições de 2002, a bancada evangélica havia recebido um impulso em seu número de integrantes, boa parte devido ao êxito dos candidatos da IURD. Depois da renúncia de seu principal representante, o ex-bispo Carlos Rodrigues, envolvido com "escândalo do mensalão", a IURD sofreu um importante desgaste em sua imagem no campo político, também por ter outros integrantes parlamentares citados na CPI das Sanguessugas. Não obstante, a cúpula da IURD proibiu que alguns de seus parlamentares, suspeitos de envolvimento em outros casos de corrupção tentassem a reeleição. Ao todo, 19 candidatos oriundos da IURD figuram no quadro II. De acordo com o a matéria do Terra:

Além da IURD, o escândalo da compra superfaturada de ambulâncias respingou sobre parlamentares integrantes de outras igrejas evangélicas, especialmente a Assembléia de Deus. Muitos deles desistiram da candidatura ou tiveram seus nomes vetados pela cúpula dessas igrejas. Outros tentaram a reeleição, mas foram barrados nas urnas. Entre os que não se reelegeram ou não se candidataram, 16 tiveram seus nomes envolvidos na máfia das ambulâncias. Não retornará para a Câmara em 2007, por exemplo, o atual coordenador da bancada evangélica, deputado Adelor Vieira (PMDB/ SC), que é membro da Assembléia de Deus. Ele é um dos acusados no relatório parcial da CPI das Sanguessugas e também está sob investigação do Ministério Público Federal. [...] A Assembléia atribui a redução da bancada a "uma jogada política" para aprovar projetos polêmicos no Congresso. Segundo o presidente do Conselho Político da igreja, Ronaldo Fonseca, houve um "massacre da mídia” em relação aos denunciados (Redação Terra, 2006).

Depois de todos estes escândalos, largamente noticiados pela mídia nacional, especialmente por terem vindo à tona próximos ao período eleitoral, desgastaram a imagem dos políticos evangélicos no que se refere à opinião pública (não que eles possuíssem uma imagem "sacralizada" anteriormente). Contudo, o que é importante de inferir com base na apuração de 2006 é que esta imagem deve ter sido abalada inclusive dentro de sua base eleitoral, ou seja, dentre os fiéis das diferentes denominaçôes. E isto não significa que tenha havido um decréscimo no número de evangélicos, por exemplo. Seguindo a tendência dos últimos levantamentos oficiais, os evangélicos são aqueles que mais crescem em número de adeptos no Brasil. De acordo com estes dados, o crescimento de adeptos nestas religiōes girou na casa de impressionantes 80\%, de 1991 para 2000 (IBGE, 2006). O que deve ter ocorrido, ao menos, é uma reanimaçáo do descrédito inerente ao imaginário coletivo a respeito da política, inclusive dentre os próprios evangélicos para com seus "candidatos oficiais".

O quadro também apresenta 17 candidatos não eleitos da Assembléia de Deus. Destes, todos foram candidatos em 2006. Esta denominação apostou na candidatura de seus membros, independentemente de estarem, alguns deles, com os nomes envolvidos em algum escândalo de corrupção. A resposta também veio nas urnas, pois dos 26 candidatos ligados a esta denominação (quadro I e II), apenas 9 se elegeram. De acordo com Ronaldo Fonseca, o presidente do Conselho Político da igreja, a redução de sua bancada na Câmara se deveu a uma "jogada política” destinada a aprovar projetos polêmicos no Congresso, graças, principalmente, ao "massacre" promovido pela mídia contra os denunciados da igreja.

Debates do NER, Porto Alegre, ANo 7, n. 10, p. 79-88, JUl./Dez. 2006 
Dos 50 políticos presentes no quadro II, mais de $70 \%$ são oriundos da Assembléia de Deus ou da IURD (36 ao todo), de fato aquelas denominaçōes evangélicas que sempre se encontraram à frente dentro da arena política. Este ano, contudo, e devido ao cálculo estratégico de preservação adotado pela IURD, a Igreja Batista assumiu o segundo posto em número de candidatos eleitos, perdendo somente para a Assembléia de Deus que, apesar de ter sentido sensivelmente os efeitos das denúncias nas urnas, permanece sendo aquela denominação com maior número de membros eleitos para a Câmara Federal em 2006.

\section{ÚLTIMAS PALAVRAS}

O fato mais importante constatado neste estudo consiste na significativa diminuição da bancada evangélica na Câmara dos Deputados depois do pleito de 2006. Apesar da religião ser tida como uma espécie de sementeira de novas energias, não obstante quando adentra o campo político, ela também não parece estar imune aos efeitos degenerativos deste campo. O caso da bancada evangélica representa bem este fenômeno. Cabe realizar um estudo (ou ao menos um levantamento) no futuro próximo para verificar se este descenso da bancada também será observado nas eleições municipais e na composição das novas Câmaras de Vereadores, daqui dois anos, ao menos nas principais capitais estaduais. Em dois anos, pode ocorre tanto uma regeneração da imagem destes candidatos e uma reformulação das estratégias eleitoreiras por parte de certas igrejas, como a IURD, quanto a permanência da tendência verificada nestas últimas eleições, que mostraram o descenso da bancada evangélica no poder legislativo.

A "regeneração" da imagem dos políticos evangélicos - o que permitiria uma retomada do espaço político perdido por estes nas últimas eleiçôes - passa por um sofisticado ar ranjo discursivo, realizado "de dentro" e "para den tro" das igrejas, ou seja, de sua cúpula institucional para seus adeptos. Este arranjo pode ser entendido da seguinte maneira: independen temente da "demonização" de alguns políticos evangélicos que ing ressaram no poder legislativo federal, dentro de suas igrejas se observa ter havido um arranjo discursivo para justificar este fenômeno; as igrejas evangélicas, corriqueiramente, declaram que seus representantes envolvidos com os escândalos de corrupção não "suportaram" e "sucumbiram" às forças do mal presentes no campo político, o que continua legitimando a representação pentecostal acerca desta dimensão pública do social. Portanto, estes devem retornar às suas igrejas a fim de se fortalecerem para depois voltar a esta frente de combate. Para alguns "corrompidos", leva mais tempo este processo, o que explica o fa to destes políticos não se candidatarem no pleito subseqüente (conforme mostrou o quadro II), mas que não necessariamente implica que eles não venham a se candidatar no futuro, uma vez "regen erados" devido ao trabalho de suas igrejas. Outros, contudo, cons eguem se "regenerar" mais rapidamente, devido ao poder de sua fé ou coisa que o valha, o que lhes permite concorrer novamente, se não tiveram seus mandatos cassados, evidentemente.

Se, por um lado, o campo político foi demonizado pelos políticos evangélicos, por outro, parte destes políticos contribuem decisivamente para que o próprio campo político seja demonizado pela sociedade.

Debates do NER, Porto Alegre, ANo 7, N. 10, P. 79-88, jul./DeZ. 2006 


\section{REFERENCIAS}

BAQUERO, Marcello. A vulnerabilidade dos partidos políticos e a crise da democracia na América Latina. Porto Alegre: Editora da UFRGS, 2000.

CORTEN, André. Pentecôtisme et politique en Amérique latine. In: Problèmes d'Amérique latine. N. 24, 1996, p. 17-32.

CORTEN, André; MARY, André. Imaginairespolitiques et pentecôtismes : Afrique/ Amérique latine. Paris: Karthala, 2000.

DIAP. Bancada Evangélica chegará menor à $53^{a}$ Legislatura. Disponível em <http:// www.diap.org.br/default.asp?codigo=8941\#8941 >. Acesso em: 17 out. 2006.

FRANCISCO, Michel Neil T. Democracia e déficit de participação política no Brasil. 2006. 120 f. Disser tação (Mestrado em Ciên cia Política) - Programa dePós-Graduaçáo em Ciên cia Política, Universidade Federal do Rio Grande do Sul, 2006.

FRIGERIO, Alejandro. Perspectivas actuales sobre conversion, deconversion y "lavado de cerebro" en nuevos movimientos religiosos. In: FRIGERIO, Alejandro (org). Nuevos movimientos religiosos y ciencias sociales. Buenos Aires: Centro Editor de América Latina, 1993.

IBGE. Censo 1991. Censo 2000. Disponível em <www.ibge.gov.br>. Acesso em: 17 out. 2006.

MICHEL, Patrick. Religion et démocratie: nouvelles situations, nouvelles approches. In: MICHEL, Patrick (org). Religión et démocratie. Paris: Albin Michel, 1997.

MOISÉS, José Álvaro. Os brasileiros e a democracia: bases sócio-políticas da legitimidade democrática. São Paulo: Editora Ática, 1995.

PNUD. La Democracia en América Latina: hacia uma democracia de ciudadanas y ciudadanos. Buenos Aires: Aguilar, Altea, Taurus, Alfaguara S.A, 2004.

ORO, Ari Pedro. Religiāo e política nas eleiçôes 2000 em Porto Alegre. In: Debates do NER, N. 3, Porto Alegre: PPGAS, 2001, p. 09-70.

REDAÇÃO TERRA. Bancada evangélica sofre redução de 75\% na Câmara. Disponível em $<$ http://no ticia s.ter ra.co m.br/ eleico es200 6/inte rna/0,,OI1 183447-EI6651,00.html>. Acesso em: 17 out. 2006.

RIBEIRO, Renato Janine. Religiāo e política no Brasil contemporâneo. In: FRIDMAN, Luis Carlos (org). Política e cultura, século XXI. Rio de Janeiro: ALERJ, Relume Dumará, 2002, p. 99-110.

TOCQUEVILlE, Alexis de. A democracia na América. São Paulo: Universidade de São Paulo, 1987. 